\title{
The Expression and Clinical Significance of ABCG2, Oct4 and Nanog in Laryngeal Carcinoma
}

\author{
Ye Nong Tan, Xiaoqin Wu*, Shufang Li, Xiang Wang, Guoqing Fu, Liu Xie, Yisha Wu, Qingyan Han \\ Chinese Medicine Hospital of Hainan Province, Haikou, China \\ Email: ${ }^{* 95197950 @ q q . c o m ~}$
}

How to cite this paper: Tan, Y.N, Wu, X.Q., Li, S.F., Wang, X., Fu, G.Q., Xie, L., $\mathrm{Wu}$, Y.S. and Han, Q.Y. (2020) The Expression and Clinical Significance of ABCG2, Oct4 and Nanog in Laryngeal Carcinoma. Journal of Cancer Therapy, 11, 660-672. https://doi.org/10.4236/jct.2020.1111056

Received: October 10, 2020

Accepted: November 15, 2020

Published: November 18, 2020

Copyright $\odot 2020$ by author(s) and Scientific Research Publishing Inc. This work is licensed under the Creative Commons Attribution International License (CC BY 4.0).

http://creativecommons.org/licenses/by/4.0/

\begin{abstract}
Objective: To investigate the protein expression and clinicopathological characteristics of ABCG2, Oct4, Nanog in laryngeal cancer tissues, and to seek new molecular markers for the diagnosis of laryngeal cancer. Methods: The laryngeal cancer tissues and paracancerous tissues of 87 patients with laryngeal carcinoma diagnosed in the department of otorhinolaryngology and head and neck surgery in our hospital from April 2016 to April 2018 were selected as the subjects. QRT-PCR, Real-time PcR, Western blot and immunohistochemical staining were used to detect the expression of ABCG2, Oct4 and Nanog in (Tumor Tissue) and (Adjacent Tissue) in tumor tissue and paracancerous tissue. Results: The results of RT-PCR showed that the positive rates of ABCG2, Oct4 and Nanog in laryngeal carcinoma tissues were $49.30 \%$, $45.07 \%$ and $52.11 \%$, respectively, while those in paracancerous tissues were $22.54 \%, 21.13 \%$ and $15.49 \%$, respectively $(\mathrm{P}<0.01)$. The expression of ABCG2, Oct4 and Nanog in laryngeal carcinoma was correlated with tumor differentiation, depth of invasion, age and $\operatorname{sex}(\mathrm{P}<0.05)$, but not with tumor size and TNM stage. Conclusion: The expressions of ABCG2, Oct4 and Nanog in cancer tissues are related to tumor differentiation status, and they can be used as new molecular markers for the diagnosis of laryngeal cancer.
\end{abstract}

\section{Keywords}

Laryngeal carcinoma, Oct4, Nanog, ABCG2, RT-PCR, Real-Time

Quantitative PCR

\section{Introduction}

In the human body, stem cells exist in the early internal cell mass (ICM), umbil- 
ical cord blood, placenta, and some adult organs and tissues. They have certain self-renewal, unlimited proliferation and differentiation potential. In recent years, with the further in-depth research on stem cells and tumors, in the human body, stem cells exist in the early internal cell mass (innercellmass, ICM), umbilical cord blood, placenta and some adult organs and tissues, and have a certain potential for self-renewal, unlimited proliferation and differentiation. In recent years, with the further study of stem cells and tumors, more and more evidence shows that there are many similarities between stem cells and tumor cells, and there is a close relationship between tumorigenesis and stem cells. Stem cells and tumor stem cells have very similar characteristics in biological characteristics and growth regulation mechanism. At present, a new theory, tumor stem cell theory, has been put forward. The isolation and detection of tumor stem cells is conducive to the further study of tumor occurrence, metastasis and recurrence, and has important guiding significance for tumor prevention, diagnosis and treatment. Laryngeal cancer accounts for $5.7 \%$ of malignant tumors in the whole body, accounting for $7.6 \%$, and the incidence rate shows an obvious increasing trend [1]. Due to the deep anatomy of the larynx, lack of specific clinical symptoms in the early stage, hoarseness and other symptoms are often mistaken by patients for upper respiratory tract infection or excessive use of voice, resulting in laryngeal cancer which is not easy to make early diagnosis, and the diagnosis is in the middle and late stage [2]. In recent years, with the improvement of comprehensive treatment measures such as minimally invasive surgery, radiotherapy, chemotherapy, simultaneous radiotherapy and chemotherapy and biotherapy, the survival time and quality of life of patients have been improved. However, the recurrence, metastasis and insensitivity to radiotherapy and chemotherapy of laryngeal cancer often lead to poor therapeutic effect, so there is an urgent need to understand the pathogenesis and recurrence mechanism of laryngeal cancer from a new perspective, so as to lay a foundation for the development of new targeted drugs for the treatment of laryngeal cancer. Octamer binding protein 4 (octamer-binding protein4, Oct4) plays an important role in maintaining self-renewal and totipotency of embryonic stem cells. Nanog is recognized as a marker gene of tumor stem cells, which can resist radiotherapy and chemotherapy, regulate tumor stem cells, remove or inactivate the gene and can inhibit the proliferation and invasion of tumor cells [3]. Embryonic stem cells (embryonicstemcell, ESCs) are pluripotent stem cells, which can differentiate into a variety of human cells, which in turn constitute various tissues and organs of the human body. For example, embryonic stem cells can be induced to differentiate into all differentiated cells including three germ layers in vitro. In animals, ESCs can differentiate into teratomas composed of three germ cells. The ability of ESCs to maintain pluripotency and self-replication involves the role of transcription factors with important functions (such as stem cell transcription factors Oct4 and Nanog) [4] [5]. They also play a very important role in the normal development of embryos and are considered to be markers of ESCs [6]. In the early process of embryonic development, Oct 4 and Nanog determine the 
fate of cell differentiation [7].

ABCG2 is an important marker of hematopoietic stem cells. In the study of hematopoietic stem cells, it was found that the group of cells transporting related efflux Hoechst33342 was rich in hematopoietic stem cells, called SP cells (sidepopulationcells) R331. MDRl is known to be an important membrane transporter, which can pump rhodamine out of the cell and is highly expressed in multifunctional hematopoietic stem cells. However, MDRl knockout mice still have SP phenotypic cells, suggesting that hematopoietic stem cells have other ABC transporters. Staud [8] studies have confirmed that many kinds of tissue-derived SP cells highly express ABCG2, and artificially increase the expression of ABCG2 by transgenic technology can make the cells show SP phenotype, so ABCG2 is the key to cause cell SP phenotype. The effect of ABCG2 on hematopoietic stem cells may be inhibitory. ABCG2 is selectively expressed in early hematopoietic cells, indicating that it plays a certain role in regulating the function of hematopoietic stem cells. Further research will help to understand the mechanism of hematopoietic stem cells maintaining non-proliferative state or entering the cell cycle. In recent years, the study of stem cell markers in solid tumors has attracted wide attention. Stem cell transcription factors Oct4 and Nanog play an important role in maintaining the pluripotency of ESCs. Tumorigenesis or formation of differentiated cells can be assumed to be the reactivation of their expression, and ABCG2 is also closely related to the formation of drug resistance in tumor cells. The relationship between them and tumor stem cells and whether they can be used as tumor stem cell markers is an urgent problem to be solved in tumorigenesis and diagnosis. Therefore, the purpose of this study is to detect the expression of stem cell markers ABCG2, Oct4 and Nanog in laryngeal carcino$\mathrm{ma}$, and to analyze the correlation with clinicopathological factors, and to explore their significance in the diagnosis of laryngeal carcinoma.

\section{Experimental Materials}

\subsection{The Source of the Case and the Collection of Samples}

A total of 87 patients with laryngeal squamous cell carcinoma treated in Hainan Provincial Hospital of traditional Chinese Medicine from April 2016 to April 2018 were selected. Inclusion criteria: 1) the clinical manifestations and pathological examination results of all patients were consistent with the diagnosis of laryngeal squamous cell carcinoma, and no tumor cells were found in adjacent tissues by pathological examination; 2) all patients with laryngeal squamous cell carcinoma were first diagnosed in Hainan Hospital of traditional Chinese Medicine. And there was no preoperative radiotherapy and chemotherapy; 3 ) the medical records were complete. Exclusion criteria: 1) poor compliance; 2) allergy to radiotherapy and chemotherapy; 3) absolute contraindications for operation. The age of 87 patients with laryngeal squamous cell carcinoma ranged from 31 to 63 years old, with average of $(39.82 \pm 7.35)$ years. There were 20 cases of supraglottic type, 46 cases of glottic type and 21 cases of subglottic type, TNM 
stage: T1-2 in 38 cases, T3-4 in 49 cases, differentiation degree: high differentiation in 32 cases, moderate and low differentiation in 55 cases, lymph node metastasis in 37 cases, no lymph node metastasis in 34 cases. The laryngeal carcinoma tissues and corresponding paracancerous tissues were collected from 87 patients with laryngeal carcinoma (distance from the edge of laryngeal carcinoma tissue $>0.5 \mathrm{~cm}$ ). The method and purpose of the experiment were informed to the patients and their families, and the informed consent was signed, and the study was approved by the hospital ethics committee.

\subsection{Main Reagents}

Total protein extraction kit (Shanghai Shenneng Biotech Co., Ltd.), BCA protein quantitative determination kit K3000 (Shanghai Shenneng Biotech Co., Ltd.), goat anti-mouse Oct antibody (Santa Cruz, USA) and mouse anti-human ABCG2 Antibody (Mitaka, Wuhan). Immunohistochemical staining kit (SP-9000) and diaminobenzidine (DAB) coloring kit were purchased from Beijing Zhongshan Jinqiao Biotechnology Co., Ltd.

\subsection{Immunohistochemical Staining Method and Result Judgment}

Using immunohistochemical staining method to detect Oct4, Nanog and the expression of ABCG2, take after surgery by paraffin embedding of laryngeal cancer tissues and adjacent tissue biopsies (thickness of 4 microns), respectively by xylene, anhydrous ethanol, phosphate buffer (phosphate buffer saline, PBS) dewaxing process, the use of $3 \%$ hydrogen peroxide inactivated endogenous peroxidase, take out the sliced, using PBS washing three times, each time $5 \mathrm{~min}$. The antigen was repaired by microwave repair method. The slices were placed in sodium citrate buffer solution with $\mathrm{pH} 6.0$, heated to boiling by microwave, and then cooled. The operation was repeated once and then washed with PBS. After cleaning, the sections were removed, sealed for $10 \mathrm{~min}$, added with primary antibody, and incubated at $4^{\circ} \mathrm{C}$ for $12 \mathrm{~h}$. After incubation, wash, successively add biotin-labeled secondary antibody and horseradish peroxidase-labeled streptomycin, and incubate at $4^{\circ} \mathrm{C}$ for $20 \mathrm{~min}$. After incubation, the samples were washed again, dyed with $\mathrm{DAB}$ chromo-developing solution for $5 \mathrm{~min}$, and then rinsed, re-dyed, dehydrated and sealed under a microscope for observation. Five high-power fields were randomly selected from each section and the number of positive staining cells was counted. According to the dyeing intensity score: colorless is 0 , light yellow is 1 , brownish yellow is 2 , and $\tan$ is 3 . Score according to the percentage of positive cells: $<5 \%$ is $0, \geq 5 \%$ and $<25 \%$ is $1, \geq 25 \%$ and $<50 \%$ is $2, \geq 50 \%$ and $<75 \%$ is $3, \geq 75 \%$ is 4 .Staining intensity score was multiplied by the percentage score of positive cells, $\leq 3$ was considered as negative expression, and $>3$ was considered as positive expression [9].

\subsection{Statistical Analysis}

The data were statistically analyzed by SPSS19.0 software, the measurement data 
were expressed by mean \pm standard deviation $(\mathrm{x} \pm \mathrm{s}$ ), the comparison between groups was carried out by $\mathrm{t}$-test, the counting data was expressed by cases and rate (\%), and the comparison between groups was analyzed by $\chi^{2}$ test, Kappa test was used for consistency analysis, Kaplan-Meier method was used to draw survival curve, and Logrank test was used for comparison between groups. Cox regression model was used for multivariate analysis. The difference was statistically significant $(\mathrm{P}<0.05)$.

\section{Results}

\subsection{Comparison of Expression of ABCG2, Oct4, Nanog}

The positive expression of Oct4 was mainly located in the nucleus and a small amount in the cytoplasm, the positive expression of Nanog was mainly located in the nucleus and a small amount in the cytoplasm, and the positive expression of Nanog was mainly located in the cell membrane. The positive expression rates of ABCG2, Oct4, and Nanog in adjacent tissues were 22.54\% (20/87), 21.13\% (18/87), $15.49 \%$ (13/87), which were significantly lower than those of $49.30 \%$ ( 43/87), $45.07 \%$ (39/87), 52.11\% (45/87), the differences were statistically significant $\left(\chi^{2}=9.191,21.275,11.045, \mathrm{P}<0.01\right)$.

\subsection{Comparison of the Positive Expression Rates of ABCG2, 0ct4 and Nanog in Laryngeal Cancer Tissues from Patients with Different Clinical Characteristics}

\subsubsection{Analysis of the Correlation between ABCG2 Expression and Clinicopathological Factors}

The positive expression of ABCG2 in laryngeal carcinoma was correlated with tumor differentiation, and the expression in low and undifferentiated groups was higher than that in moderately and well differentiated groups and it was related to age, gender and lymph node metastasis, but not to tumor size, depth of invasion and TNM staging. The results are shown in Table 1.

\subsubsection{Correlation Analysis between Oct4 Expression and Clinicopathological Parameters}

The positive expression of Oct4 in laryngeal carcinoma was correlated with tumor differentiation, and it was higher in low and undifferentiated groups than in moderately and well differentiated groups, lymph node metastasis and gender, but not related to age, tumor size, depth of invasion and TNM stage. The results are shown in Table 2.

\subsubsection{Analysis of the Correlation between Nanog Expression and Clinicopathological Parameters}

The positive expression of Nanog in laryngeal carcinoma was correlated with tumor differentiation, and the expression in low and undifferentiated groups was higher than that in moderately and well differentiated groups and it was related to age, lymph node metastasis and depth of invasion, but not to gender, tumor size and TNM stage. The results are shown in Table 3. 
Table 1. Correlation analysis of ABCG2 expression and clinicopathological parameters in laryngeal carcinoma.

\begin{tabular}{|c|c|c|c|c|c|c|}
\hline \multicolumn{7}{|c|}{ ABCG2 mRNA positive } \\
\hline Clinicopathological & & $\mathrm{n}$ & Case & $\begin{array}{c}\text { Number } \\
\text { rate } \%\end{array}$ & $\begin{array}{c}\text { Parameter } \\
\chi^{2} \text {-value }\end{array}$ & PP-value \\
\hline \multirow{2}{*}{ Age (ys) } & $\leq 60$ & 57 & 19 & $(33.33)$ & 17.1241 & 0.0001 \\
\hline & $>60$ & 30 & 24 & $(80.00)$ & & \\
\hline \multirow{2}{*}{ Gender } & Male & 45 & 28 & $(62.22)$ & 9.0428 & 0.0026 \\
\hline & Female & 43 & 13 & $(30.23)$ & & \\
\hline \multirow{2}{*}{ Tumor size $(\mathrm{cm})$} & $\leq 5$ & 35 & 17 & $(48.57)$ & 1.0317 & 0.3098 \\
\hline & $>5$ & 52 & 31 & $(59.62)$ & & \\
\hline \multirow{2}{*}{ TNM Staging } & $\mathrm{I}+\mathrm{II}$ & 41 & 18 & $(43.90)$ & 0.3235 & 0.5695 \\
\hline & $\mathrm{III}+\mathrm{IV}$ & 46 & 23 & $(50.00)$ & & \\
\hline \multirow{2}{*}{ Differentiation Grade } & medium and well differentiated & 53 & 18 & $(33.96)$ & 14.9727 & 0.0001 \\
\hline & Low undifferentiated & 34 & 26 & $(76.47)$ & & \\
\hline \multirow{2}{*}{ Infiltration depth } & $\mathrm{T} 1, \mathrm{~T} 2$ & 41 & 16 & $(39.02)$ & 2.6579 & 0.1030 \\
\hline & $\mathrm{T} 3, \mathrm{~T} 4$ & 46 & 26 & $(56.52)$ & & \\
\hline \multirow{2}{*}{ Lymph node metastasis } & Yes & 42 & 39 & $(92.86)$ & 34.7892 & 0.0001 \\
\hline & No & 45 & 14 & $(31.11)$ & & \\
\hline
\end{tabular}

Note: Comparison between groups, $\mathrm{P}<0.05$.

Table 2. Correlation analysis of Oct-4 expression and clinicopathological parameters in laryngeal carcinoma tissue.

\begin{tabular}{|c|c|c|c|c|c|c|}
\hline \multicolumn{7}{|c|}{ Oc14 mRNA positive } \\
\hline Clinicopathological & & $\mathrm{n}$ & Case & $\begin{array}{c}\text { Number } \\
\text { rate } \%\end{array}$ & $\begin{array}{l}\text { Parameter } \\
\chi^{2} \text {-value }\end{array}$ & PP-value \\
\hline \multirow{2}{*}{ Age (ys) } & $\leq 60$ & 57 & 25 & $(43.86)$ & 2.0484 & 0.1524 \\
\hline & $>60$ & 30 & 18 & $(60.00)$ & & \\
\hline \multirow{2}{*}{ Gender } & Male & 45 & 34 & $(75.56)$ & 6.1015 & 0.0135 \\
\hline & Female & 43 & 21 & $(50.00)$ & & \\
\hline \multirow{2}{*}{ Tumor size $(\mathrm{cm})$} & $\leq 5$ & 35 & 21 & $(60.00)$ & 0.1532 & 0.6955 \\
\hline & $>5$ & 52 & 29 & $(55.77)$ & & \\
\hline \multirow{2}{*}{ TNM Staging } & $\mathrm{I}+\mathrm{II}$ & 41 & 16 & $(39.02)$ & 2.6579 & 0.1030 \\
\hline & $\mathrm{III}+\mathrm{IV}$ & 46 & 26 & $(56.52)$ & & \\
\hline \multirow{2}{*}{ Differentiation Grade } & medium and well differentiated & 53 & 20 & $(37.74)$ & 7.4135 & 0.0065 \\
\hline & Low undifferentiated & 34 & 23 & $(67.65)$ & & \\
\hline \multirow{2}{*}{ Infiltration depth } & $\mathrm{T} 1, \mathrm{~T} 2$ & 41 & 18 & $(43.90)$ & 1.8999 & 0.1681 \\
\hline & T3, T4 & 46 & 27 & $(58.70)$ & & \\
\hline \multirow{2}{*}{ Lymph node metastasis } & Yes & 42 & 30 & (71.43) & 12.6259 & 0.0004 \\
\hline & No & 45 & 15 & (33.33) & & \\
\hline
\end{tabular}

Note: Comparison between groups, $\mathrm{P}<0.05$. 
Table 3. Correlation analysis of Nanog expression and clinicopathological parameters in laryngeal carcinoma tissue.

\begin{tabular}{|c|c|c|c|c|c|c|}
\hline \multicolumn{7}{|c|}{ Nanog mRNA positive } \\
\hline Clinicopathological & & $\mathrm{n}$ & Case & $\begin{array}{l}\text { Number } \\
\text { rate } \%\end{array}$ & $\begin{array}{c}\text { Parameter } \\
\chi^{2} \text {-value }\end{array}$ & PP-value \\
\hline \multirow{2}{*}{ Age (ys) } & $\leq 60$ & 57 & 13 & $(22.81)$ & 35.7277 & 0.0001 \\
\hline & $>60$ & 30 & 27 & $(90.00)$ & & \\
\hline \multirow{2}{*}{ Gender } & Male & 45 & 25 & $(55.56)$ & 1.4014 & 0.2365 \\
\hline & Female & 42 & 18 & $(42.86)$ & & \\
\hline \multirow{2}{*}{ Tumor size $(\mathrm{cm})$} & $\leq 5$ & 35 & 12 & $(34.29)$ & 0.8605 & 0.3536 \\
\hline & $>5$ & 52 & 23 & $(44.23)$ & & \\
\hline \multirow{2}{*}{ TNM Staging } & $\mathrm{I}+\mathrm{II}$ & 41 & 15 & $(36.59)$ & 3.4579 & 0.0630 \\
\hline & $\mathrm{III}+\mathrm{IV}$ & 46 & 26 & $(56.52)$ & & \\
\hline \multirow{2}{*}{ Differentiation Grade } & medium and well differentiated & 53 & 16 & $(30.19)$ & 15.6144 & 0.0001 \\
\hline & Low undifferentiated & 34 & 25 & $(75.53)$ & & \\
\hline \multirow{2}{*}{ Infiltration depth } & $\mathrm{T} 1, \mathrm{~T} 2$ & 41 & 12 & $(29.27)$ & 6.5452 & 0.0105 \\
\hline & $\mathrm{T} 3, \mathrm{~T} 4$ & 46 & 26 & $(56.62)$ & & \\
\hline \multirow{2}{*}{ Lymph node metastasis } & Yes & 42 & 23 & $(54.76)$ & 7.1314 & 0.0076 \\
\hline & No & 45 & 12 & (26.67) & & \\
\hline
\end{tabular}

Note: Comparison between groups, $\mathrm{P}<0.05$.

\section{Discussion}

Laryngeal carcinoma is the most common malignant tumor in the head and neck. The main clinicopathological type is laryngeal squamous cell carcinoma (Laryngeal Squamous Cell Carcinoma, LSCC) [10] [11] [12]. Although the diagnosis and treatment of laryngeal squamous cell carcinoma has improved with the development of medical counting, the survival rate of patients with laryngeal carcinoma is still at a low level in the past 30 years [13] [14]. In-depth study and revelation of the molecular mechanism of laryngeal squamous cell carcinoma, especially the mechanism of its formation of distal metastatic lesions, is conducive to its early diagnosis and treatment and the formulation of corresponding clinical treatment [15] [16] [17].

\subsection{Expression of ABCG2 in Tumors}

As a newly discovered member of $\mathrm{ABC}$ transporter family, $\mathrm{ABCG} 2$ plays a more and more important role in tumor drug resistance. At present, $A B C G 2$ has been reported in breast cancer, brain tumor, lung cancer, nasopharyngeal carcinoma, leukemia and other malignant tumors [18] [19] [20] [21] [22] Most studies suggest that the expression of ABCG2 is related to prognosis. Burger et al. analyzed 59 patients with primary breast cancer who were treated with fluorouracil, doxorubicin, cyclophosphamide or cyclophosphamide combined with cyclophosphamide, methotrexate and fluorouracil by RT-PCR. The results showed that the 
expression level of ABCG2mR_NA was correlated with survival rate in these patients. The results of Benderra et al. [23] showed that in the newly diagnosed acute leukemia group, the positive expression rate of ABCG2 was $37.6 \%$. The first complete remission rates of $\mathrm{ABCG}$ 2rnRNA negative and positive patients were $79.3 \%$ and $31.6 \%$, respectively. The level of ABCG2mRNA in recurrent group was significantly higher than that in recurrent group. ABCG2 has been widely studied in acute granulocytic autoimmune disease, and it is considered that it is related to drug resistance of AML. Using its ability to pump out Hoechst33342, it is used to isolate and study stem cells, which accumulate little fluorescent material called marginal cell (sidepopulmioncells). Therefore, ABCG2 is also a commonly used molecular marker to study the drug resistance of tumor stem cells. However, the expression, distribution and physiological function of ABCG2 and its relationship with tumor need to be further studied. This study found that the positive expression of ABCG2 in laryngeal carcinoma was related to tumor differentiation, and the expression of ABCG2 in low and undifferentiated groups was higher than that in moderately and well differentiated groups and it was related to age, sex and lymph node metastasis, but not to tumor size, depth of invasion and TNM stage. It suggests that abnormal expression of ABCG2 may be related to invasion and metastasis of laryngeal carcinoma, and may provide a reference basis for early diagnosis and evaluation of laryngeal carcinoma.

\subsection{The Expression of Oct4 in Adult Tissues}

The expression of Oct4 in adult tissues is mainly limited to cells with stem cell characteristics. Gup et al. [24] found Oct4 FE-expressing cells in stem cells in human breast, liver, pancreas, kidney, mesenchymal and stomach tissues and in the basal layer of human and dog skin. It is considered that these Oct4-positive cells are pluripotent stem cells. In addition, hOct4 expression was found in normal striated muscle tissue and skin tissue [25]. Ratajczak et al. [26] proved that the expression of Oct4, in adult tissues includes pluripotent stem cells stored during early gastrula embryogenesis (embryogenesis). Adult tissues containing adult stem cells include mesenchymal stem cells derived from epidermis, bronchial epithelium, myocardial membrane, pancreas, testis and bone marrow. The expression of Oct4 is down-regulated during stem cell differentiation, but decreased or absent in differentiated cells in adult tissues. The Oct4 positive cells found in adult tissues may be related to the appropriate somatic cell cloning ability. Because Oct4-positive cells are related to the characteristics of stem cells, it has become one of the important research contents in the field of tissue engineering. The results showed that the positive expression rate of Oct4 in laryngeal carcinoma was higher than that in paracancerous tissues, and its expression was related to the differentiation status of laryngeal carcinoma, and the expression in low and undifferentiated groups was higher than that in moderately and well differentiated groups, lymph node metastasis and sex. The survival rate of pa- 
tients with positive expression of Oct4 is lower than that of patients with negative expression, suggesting that Oct4 is involved in the occurrence and development of laryngeal carcinoma and is expected to be used as a new target for the treatment of laryngeal cancer and a predictor of prognosis in patients with laryngeal carcinoma.

\subsection{Expression of Nanog in Tumors}

At present, in addition to the study of the role of Nanog in ESCs@, there are many studies on the relationship between Nanog and embryonic cancer cells and germ cell tumors. Nanog is specifically highly expressed in testicular carcinoma in situ, embryonal tumors and seminoma [27] [28]. It is considered that the high expression of NaIlog and Oct4 is the marker of stem cell totipotent preinvasive testicular cancer cells. Recently, more and more attention has been paid to the relationship between Nanog and somatic solid tumors. For example, CSCs cells with stem cell-like characteristics that stimulate tumor formation have been found in breast cancer, brain tumors, bladder cancer and osteosarcoma [29] [30] [31]. Zhang et al. [32] detected the expression of Nanog pseudogene 8 (highly homologous to Nanog) in cervical cancer, breast cancer and bladder cancer. In this study [33], it was found that the positive expression rate of Nanog in laryngeal carcinoma was higher than that in adjacent tissues, and it was related to the differentiation status of laryngeal carcinoma, and it was higher in low and undifferentiated groups than in moderately and well differentiated groups, and it was also related to age, lymph node metastasis and depth of invasion. The survival rate of patients with positive expression of Nanog was lower than that of patients with negative expression of Nanog, and the expression of Nanog was an independent risk factor affecting the prognosis of laryngeal carcinoma, which was consistent with the results of related studies. It is suggested that Nanog can be used as a new target for the diagnosis and treatment of laryngeal carcinoma.

\section{Limitations of the Research Results}

The results of this study showed that Oct4 and Nanog can act as new oncogenes, which may participate in cell dedifferentiation and act as markers of tumor stem cells. Excessive proliferation of residual laryngeal stem cells or the reversal of normal laryngeal stem cells into tumor stem cells can lead to the occurrence and development of laryngeal cancer. The positive and co-expression of Oct4, Nanog and ABCG2 in the cancer tissues of patients with laryngeal cancer is related to the recurrence after radiotherapy and chemotherapy. Survival analysis for prognostic assessment will be followed up for further study.

1) The expression levels of ABCG2, Oct4, and Nanog in laryngeal cancer tissues were higher than those in adjacent tissues, indicating that laryngeal cancer tissues may contain stem cell-like cells with self-renewal and differentiation potential, namely tumor stem cells, which further provides new evidence for the theory of tumor stem cells in tumor genesis. 
2) The expression of stem cell markers ABCG2, Oct4, and Nanog in laryngeal cancer tissues was correlated with their degree of differentiation. The low and undifferentiated groups were higher than the medium and highly differentiated groups. Oct4, Nanog and ABCG2 are related to the occurrence, development and differentiation of laryngeal cancer, and can play a role in the diagnosis of new molecular markers of laryngeal cancer.

The hypopharyngeal cancer tissues resected by Cui Haojing et al. [34]. In the Otorhinolaryngology Head and Neck Surgery department of The Affiliated Hospital of Inner Mongolia Medical University from March 2011 to May 2014 were selected as the research objects, and the para-cancer mucosal tissues of 24 of them were selected as the control. Enzyme-linked immunosorbent assay (EUSA) was used to determine the content of B-catenin, OCT-4 and Nanog proteins in hypopharyngeal cancer tissues and adjacent mucosal tissues, and immunohistochemical method was used to determine the expressions of B-catenin, OCT-4 and Nanog proteins in the two tissues. The study found that the expression rates of B-catenin, Oct4 and Nanog proteins showed no statistical difference in different age groups (all $\mathrm{P}$ was $>0.05$ ). There were no statistically significant differences in the expression rates of B-catenin, oct-4 and Nanog proteins in different ages (all $\mathrm{P}$ was $>0.05$ ). The positive expression rates of B-catenin, OCT-4 and Nanog proteins were higher in patients with high pathological stage, deep infiltration, lymph vessel space infiltration and lymph node metastasis, and the differences were statistically significant (All $\mathrm{P}<0.05$ ). This study is consistent with the conclusions of this study.

\section{Conclusion}

To sum up, the abnormal expression of ABCG2, Oct4 and Nanog in laryngeal carcinoma is related to the degree of differentiation and lymph node metastasis of laryngeal carcinoma, suggesting that they may be involved in the development and metastasis of laryngeal cancer and their mechanism of action on laryngeal carcinoma may be partially related. The combined detection of the three may be an ideal diagnostic method and have a certain application value in guiding the clinical treatment of laryngeal carcinoma and judging the prognosis of patients.

\section{Funding}

This work was supported by the Hainan Key Research and Development Plan (DYF2017116).

\section{Conflicts of Interest}

The authors declare no conflicts of interest regarding the publication of this paper.

\section{References}

[1] Warner, L., Chudasama, J., Kelly, C.G., Loughran, S., McKenzie, K., Wight, R. and 
Dey, P. (2014) Radiotherapy versus Open Surgery versus Endolaryngeal Surgery (with or without Laser) for Early Laryngeal Squamous Cell Cancer. Cochrane Database of Systematic Reviews, No. 12, Article No. CD002027. https://doi.org/10.1002/14651858.CD002027.pub2

[2] MacNeil, S.D., Liu, K., Shariff, S.Z., Thind, A., Winquist, E., Yoo, J., et al. (2015) Secular Trends in the Survival of Patients with Laryngeal Carcinoma, 1995-2007. Current Oncology, 22, e85-e99. https://doi.org/10.3747/co.22.2361

[3] Zhang, X., Xu, M., Liu, Y., et al. (2016) Research Progress of Stem Cell Factor Nanog in Tumors. Cancer Research on Prevention and Treatment, 43, 295-299.

[4] Brchm, A., Ohbo, K. and Scholer, H. (1997) The Carboxy-Terminal Transactivation Domain of Oct-4 Acquires Cell Specificity through the POU Domain. Molecular and Cellular Biology, 17, 154-162. https://doi.org/10.1128/MCB.17.1.154

[5] Vigano, M.A. and Staudt, L.M. (1996) Transcriptional Activation by Oct-3: Evidence for Aspecific Role of the POU-Specific Domain in Mediating Transcription Interaction with Oct-1. Nucleic Acids Research, 24, 2112-2118. https://doi.org/10.1093/nar/24.11.2112

[6] Liu, L., Leaman, D., Villalta, M., et al. (1997) Silencing of the Gene for the Alpha-Subunitof Human Chorionic Gonadotropin by the Embryonic Transcription Factor Oct-3/4. Molecular Endocrinology, 11, 1651-1658.

[7] Pesce, M. and Scholer, H. (2000) Oct-4: Control of Totipotency and Germline Determination. Molecular Reproduction and Development, 55, 452-457.

https://doi.org/10.1002/(SICI)1098-2795(200004)55:4<452::AID-MRD14>3.0.CO;2$\underline{S}$

[8] Staud, F. and Pavek, P. (2005) Breast Cancer Resistance Protein (BCRP/ABCG2). The International Journal of Biochemistry \& Cell Biology, 37, 720-725. https://doi.org/10.1016/j.biocel.2004.11.004

[9] Ravindran, G., Sawant, S.S., Hague, A., et al. (2015) Association of Differential $\beta$-Catenin Expression with Oct-4 and Nanog in Oral Squamous Cell Carcinoma and Their Correlation with Clinicopathological Factors and Prognosis. Head \& Neck, 37, 982-993. https://doi.org/10.1002/hed.23699

[10] Zhou, L.D., Cui, Y. and Dong, C. (2018) The Mechanism of Curcumin Combined with Resveratrol in Inducing Apoptosis of Human Laryngeal Carcinoma Cell Hep-2. Journal of Shenyang Pharmaceutical University, 12, 67-72.

[11] Baird, B.J., Sung, C.K., Beadle, B.M. and Divi, V. (2018) Treatment of Early-Stage Laryngeal Cancer: A Comparison of Treatment Options. Oral Oncology, 87, 8-16. https://doi.org/10.1016/j.oraloncology.2018.09.012

[12] Sun, J.F. and He, H.T. (2018) Mechanism of Baicalein Inducing Apoptosis of Laryngeal Carcinoma Cells in vitro through Mitochondrial Apoptosis Pathway. Chinese Journal of Gerontology, 21, 1947-1951.

[13] Wang, X. and Sun, Y.N. (2017) Research Progress of Non-Coding RNA in Laryngeal Squamous Cell Carcinoma. Chinese Journal of Clinical Oncology, 15, 1204-1207.

[14] Lopez-Ayllon, B.D., Moncho-Amor, V., Abarrategi, A., et al. (2014) Cancer Stem Cells and Cisplatin-Resistant Cells Isolated from Non-Small-Lung Cancer Cell Lines Constitute Related Cell Populations. Cancer Medicine, 3, 1099-1111. https://doi.org/10.1002/cam4.291

[15] Gan, H.Y., Du, J.D., Hong, O.Y., et al. (2018) Effects and Mechanisms of Phenethyl Isothiocyanate on the Proliferation, Apoptosis, Cycle, Invasion and Metastasis of Laryngeal Carcinoma Hep-2 Cells. Chinese Journal of Gerontology, 32, 5529-5533. 
[16] Wang, L., Sun, J. and Cao, H. (2018) MicroRNA-384 Regulates Cell Proliferation and Apoptosis through Directly Targeting WISP1 in Laryngeal Cancer. Journal of Cellular Biochemistry, 120, 3018-3026. https://doi.org/10.1002/jcb.27323

[17] Miyamaru, S., Minoda, R. and Kodama, N. (2018) Long-Term Changes in Vocal Function after Supracricoid Partial Laryngectomy with Cricohyoidoepiglottopexy for Laryngeal Cancer. Head \& Neck, 41, 139-145. https://doi.org/10.1002/hed.25487

[18] Hirschmann-Jax, C., Foster, A.E., Wulf, G.G., et al. (2005) A Distinct “Side Population" of Cells in Human Tumor Cells: Implications for Tumor Biology and Therapy. Cell Cycle, 4, 203-205.

[19] Kawabata, S., Oka, M., Soda, H., et al. (2003) Expression and Functional Analyses of Breast Cancer Resistance Protein in Lung Cancer. Clinical Cancer Research, 23, 345-356.

[20] Hirschmann-Jax, C., Foster, A.E., Wulf, G.G., Nuchtern, J.G., Jax, T.W., Gobel, U., Goodell, M.A. and Brenner, M.K. (2004) A Distinct "Side Population" of Cells with High Drug Efflux Capacity in Human Tumor Cells. Proceedings of the National Academy of Sciences of the United States of America, 101, 14228-14233. https://doi.org/10.1073/pnas.0400067101

[21] Wulf, G.G., Wang, R.Y., Kuehnle, I., et al. (2001) A Leukemic Stem Cell with Instrinsic Drugeffiux Capacity in Acute Myeloid Leukemia. Blood, 98, 1166-1173. https://doi.org/10.1182/blood.V98.4.1166

[22] Burger, H. and Foekens, J.A. (2003) RNA Expression of Breast Cancer Resistance Protein, Lung Resistance-Related Protein, Multidrug Resistance-Associated Proteins 1 and 2, and Multidrug Resistance Gene 1 in Breast Cancer: Correlation with Chemotherapeutic. Clinical Cancer Research, 9, 827-836.

[23] Benderra, Z., Faussat, A.M., Sayada, L., Perrot, J.-Y., Chaoui, D., Marie, J.-P. and Legrand, O. (2004) Breast Cancer Resistance Protein and P-Glycoprotein in 149 Adult Acute Myeloid Leukemis. Clinical Cancer Research, 10, 7896-7902. https://doi.org/10.1158/1078-0432.CCR-04-0795

[24] Gupta, S., Verfaillie, C., Chmielewski, D., et al. (2006) Isolation and Characterization of Kidney-Derived Stem Cells. Journal of the American Society of Nephrology, 17, 3028-3040. https://doi.org/10.1681/ASN.2006030275

[25] Suo, G.L., Han, J., Wang, X., Kren, S., Dai, J.W., Eidman, K. and Connaire, J. (2005) Oct-4 Pseudogenes Are Transcribed in Cancers. Biochemical and Biophysical Research Communications, 337, 1047-1051. https://doi.org/10.1016/j.bbrc.2005.09.157

[26] Ratajczak, M.Z., Machalinski, B., Wojakowski, W., et al. (2007) A Hypothesis for Anembryonic Origin of Pluripotent Oct $-4^{+}$Stem Cells in Adult Bone Marrow and Other Tissues. Leukemia, 21, 860-867. https://doi.org/10.1038/sj.leu.2404630

[27] Ye, F., Zhou, C.Y., Cheng, Q., Shen, J.J. and Chen, H.Z. (2008) Stem-Cell-Abundant Proteins Nanog, Nucleostemin and Musashil Are Highly Expressed in Malignant Cervical Epithelial Cells. BMC Cancer, 8, Artice No. 108. https://doi.org/10.1186/1471-2407-8-108

[28] Hart, A.H., Hartley, L., Parker, K., et al. (2005) The Pluripotency Homeobox Gene Nanog Isexpressed in Human Germ Cell Tumors. Cancer, 104, 2092-2098. https://doi.org/10.1002/cncr.21435

[29] Kuroda, T., Tada, M., Kubota, H., Kimura, H., Hatano, S.-Y, Suemori, H., Nakatsuji, N. and Tada, T. (2005) Octamer and Sox Elements Are Required for Transcriptional cis Regulation of Nanog Gene Expression. Molecular and Cellular Biology, 25, 2475-2485. https://doi.org/10.1128/MCB.25.6.2475-2485.2005

[30] Singh, S.K., Clarke, I.D., Terasaki, M., Bonn, V.E., Hawkins, C., Squire, J. and Dirks, 
P.B. (2003) Identification of a Cancer Stem Cell Inhuman Brain Tumors. Cancer Research, 63, 5821-5828.

[31] Wilson, H., Huelsmeyer, M., Chun, R., Young, K.M., Friedrichs, K. and Argyle, D.J. (2008) Isolation and Characterisation of Cancer Stem Cells from Canine Osteosarcoma. The Veterinary Journal, 175, 69-75. https://doi.org/10.1016/j.tvjl.2007.07.025

[32] Zhang, J., Wang, X., Li, M., Han, J., Chen, B., Wang, B. and Dai, J. (2006) NANOGP8 Is a Retrogene Expressed in Cancers. The FEBS Journal, 273, 1723-1730. https://doi.org/10.1111/j.1742-4658.2006.05186.x

[33] Rodrigo, J.P., Villaronga, M.Á, Menéndez, S.T., et al. (2017) A Novel Role for Nanog as an Early Cancer Risk Marker in Patients with Laryngeal Precancerous Lesions. Scientific Reports, 7, Article No. 11110. https://doi.org/10.1038/s41598-017-11709-9

[34] Cui, H.J., Sun, J. and Wei, X.J. (2018) Expression and Clinical Significance of B-Catenin, OCT-4 and Nanog in Hypopharyngeal Carcinoma. Chinese Journal of Clinical Research, 31, 1305-1309. 